\title{
Research Article Fund-Raising Games Played on a Network
}

\author{
Alison Watts \\ Department of Economics, Southern Illinois University, Carbondale, IL 62901, USA \\ Correspondence should be addressed to Alison Watts; wattsa@siu.edu
}

Received 30 August 2013; Accepted 1 October 2013

Academic Editors: D. Dave, D. Mitra, and E. Silva

Copyright (C 2013 Alison Watts. This is an open access article distributed under the Creative Commons Attribution License, which permits unrestricted use, distribution, and reproduction in any medium, provided the original work is properly cited.

It is well known among fund-raisers that many people contribute to charities or organizations only when asked and that large donations are more likely to occur as a fund-raiser increases the time spent soliciting and/or researching a potential donor. As fund-raisers can only spend time with research donors that they are aware of, the relationship (or links) between fund-raisers and donors is quite important. We model a fund-raising game where fund-raisers can only solicit donors whom they are tied to and analyze how this network influences donation requests. We show that if this network is incomplete and if donors experience extreme donor fatigue, then fund-raisers will spend more time soliciting donors that other fund-raisers are also tied to and less time soliciting donors that they are the only fund-raiser tied to. If instead donors experience mild donor fatigue, then fund-raisers prefer donors that they are the only fund-raiser tied to over donors that are shared with other fund-raisers. If donors are potential givers with no donor fatigue, then multiple equilibria may exist. Stochastic stability is used to refine the number of equilibria in this case, and conditions are given under which the unique stochastically stable equilibrium is efficient.

\section{Introduction}

In 2005, seventy percent of all US households gave to charity donations totalling over $\$ 200$ billion; see Andreoni [1]. In Canada, private donations to charity represent approximately two percent of GDP (this figure includes volunteer time; private monetary donations to charity represent approximately one percent of GDP.); see Hall et al. [2]. This high charitable contribution rate is due in part to the "power of the ask" as most people contribute to charities or organizations only when asked; see Yörük [3], Yörük [4], Andreoni [5], Andreoni and Payne [6], and Keegan [7]. Large donations are more likely to occur as a fund-raiser increases the time spent with the potential donor and/or increases the time spent researching the potential donor. (For instance, Dellavigna et al. [8] compare donation rates from a door to door fund-raising drive to donations received via the mail or the Internet. They find that the mail and Internet donation rate is around 0.0001 percent while the face to face donation rate is over 6 percent. Thus, fund-raisers can greatly increase donations by using the more time consuming face to face solicitation technique.) However, a fund-raiser can only research or solicit a donor that he is aware of or has some sort of tie to; for instance, a fund-raiser may research or solicit a donor who has responded in the past to a mail out campaign. Thus, the relationship or ties between fundraisers and donors is quite important. However, the network of ties between fund-raisers and donors and this network's influence on donations has not been explored in the fundraising literature. We analyze such a network and examine how this network influences "the ask" or donation requests.

In particular, we show that if the fund-raiser donor network is incomplete, then whether or not a fund-raiser shares a donor tie with other fund-raisers becomes important and will influence donation requests. For instance, if donors experience extreme "donor fatigue," then fund-raisers prefer shared donor ties, while if donors experience mild "donor fatigue" then fund-raisers prefer unshared donor ties. Additionally, if donors are identified as potential givers with no "donor fatigue," then multiple equilibria may exist. We use stochastic stability to refine the number of equilibria and give conditions under which the unique stochastically stable state is efficient.

The basic model and results are as follows. Fund-raisers are tied to donors in a network, and fund-raisers may only ask donors whom they are tied to for donations. (Some 
companies sell donor information; thus, a fund-raiser may learn of a donor in this fashion and may decide to research and solicit him. We model this as just an existing tie between the fund-raiser and donor. Thus, we assume a fixed network for tractability purposes and discuss the endogenous network case in the conclusion.) If multiple fund-raisers are tied to the same donor, then they compete with each other for donations in an average donation sharing game. In such a game, a donor's total donation increases as the total time all fundraisers spend with the donor increases and donations are split among fund-raisers in proportion to the time each fundraiser spends soliciting or researching the donor. (Note that we assume that donors are homogeneous or that a donor's donation to a particular fund-raiser depends only on time spent with the donor by each fund-raiser and does not depend on the identity of the donor. We make this assumption because our focus is on how the fund-raiser donor network affects solicitation time and assuming homogeneous donors allows us to concentrate on this network effect.) If there is a monopoly fund-raiser who is tied to all donors, then this fund-raiser splits his solicitation efforts evenly among all donors if donors experience "donor fatigue" or if donations increase at a decreasing rate with solicitation time, and thus donors become less and less responsive to solicitation appeals. The monopoly fund-raiser picks a single donor and spends all his time soliciting this donor if donors are thought of as potential givers with no donor fatigue whose donations increase at an increasing rate with solicitation time. These results are echoed if multiple fund-raisers compete on the complete network where every fund-raiser is tied to every donor. Here, fund-raisers split their solicitation efforts evenly among donors if donor fatigue is present or if the returns to solicitation time are increasing at a decreasing rate, while all fund-raisers spend all their time soliciting the same donor if the returns to solicitation time are increasing at an increasing rate.

The results change if the fund-raiser donor network is incomplete or if not all donors are tied to all fund-raisers. For instance, alumni donors are tied to colleges and/or universities that they attended and not to all institutions, religious donors are tied to religious organizations of which they are members, and charities in general have lists of donors who have responded to past mail out campaigns where again not all donors will respond to all campaigns.

First, we assume that donors experience donor fatigue or that donations are increasing at a decreasing rate with time spent soliciting donations. (Donor fatigue as defined in Yörük [4] occurs when a donor is solicited repeatedly and eventually stops giving or gives less than he gave previously. In our model, donors are not asked to give repeatedly instead fund-raisers decide how much effort or time to spend with a donor and donations occur at the end of this time. Thus, in our model donor fatigue occurs when each unit of time spent by the fund-raiser with a particular donor results in a smaller marginal donation than the previous unit. Note that one can reinterpret our model as allowing donations to flow to the fund-raiser after each unit of time spent soliciting a particular donor. Donations would then decrease with repeated solicitation, and the two definitions of donor fatigue would coincide.) Here, fund-raisers will no longer split their time evenly among donors. In an incomplete network, some fund-raisers may have access to donors that others do not while other donors may be tied to multiple fund-raisers. If donors experience extreme donor fatigue or if the donation-solicitation function is fairly curved, then as a fund-raiser spends extra time with a donor although the total donation does not increase much the fund-raiser's share of the donation increases quite a bit. Thus, the fund-raiser spends more time soliciting donors that other fund-raisers are also tied to and less time soliciting donors that he is the only fund-raiser tied to. Although one might expect fundraisers to prefer shared donor ties for any concave donorsolicitation function, we find that this is not the case. If donors experience mild donor fatigue or if the donation-solicitation function is not as curved, then the fund-raiser prefers unshared donor ties and the fund-raiser will spend more time soliciting donors that other fund-raisers are not tied to and less time soliciting donors that other fund-raisers are also tied to.

Next, we consider donors who experience no donor fatigue, and we allow donations to increase in solicitation time at an increasing rate. Here all fund-raisers would prefer to solicit the same donor. If the network is incomplete, then this may not be possible. Even if there exists a donor who all fund-raisers are tied to, not all fund-raisers will have access to every other donor and multiple equilibria will exist. At most equilibria, multiple donors will be solicited since once a fundraiser solicits a potential donor, the incompleteness of the network may not allow other fund-raisers also to solicit this same donor; there can exist a large number of these inefficient equilibria. As the number of equilibria may be quite large, stochastic stability is used in order to refine the number of equilibria. Trembles or mistakes are allowed to occur where after a fund-raiser has decided how much time to spend with a donor, there is a positive probability that a mistake occurs and that his solicitation decisions are reallocated. If the network is such that there is a donor whom all fund-raisers are tied to, then at the unique stochastically stable state all fund-raisers will solicit this donor which coincides with the efficient Nash equilibrium.

Our paper contributes to several literatures. First, it contributes to the literature on the strategic analysis of fundraising. Andreoni [5] offers an excellent literature review on this topic. This literature answers questions such as how fundraisers react to government grants (see Andreoni and Payne [6]) as well as how competition among charities can result in too many or too few solicitations (see Mungan and Yörük [9] and Yörük [4]). Our paper adds to this literature by allowing fund-raisers to behave strategically while competing for donations on a network. Other fund-raising literatures analyze the strategic behavior of donors in a public good context. (For simplicity, we do not model the strategic behavior of donors explicitly but focus instead on competition between fund-raisers on a network. Similarly, in models of Cournot competition firms are modeled as strategic players and the strategic behavior of consumers is not modeled explicitly, but instead consumers are assumed to follow a demand function. In our model, donors follow a donation function 
based on the time fund-raisers spend soliciting donations which is similar in spirit to the assumption of Andreoni and Payne [6] that donors only donate if asked.) See Marx and Matthews [10], Bagnoli and Lipman [11], and Andreoni [5] for a literature review. Recent empirical studies show that fund-raising behavior is crucial to donations; see Yörük [3], Yörük [4], and Dellavigna et al. [8]. Additionally, Meer and Rosen [12] document the importance of personal solicitations in fund-raising, van Diepen et al. [13] document the effect of direct mailings on donations, and Andreoni and Rao [14] show experimentally the importance of asking for a donation.

Second, our paper contributes to the literature on economic and social networks; a literature review is given by Jackson [15], and Jackson and Wolinsky [16] is a founding paper of this literature. Specifically, our model adds to the literature on applications of social and economic networks. In our model, donations or money can only flow along social links. Previous papers have looked at the flow of information regarding coauthors or job prospects along links (see Jackson and Wolinsky [16] and Calvó-Armengol and Jackson [17]) as well as the flow of financial help along social links in developing countries (see Bramoullé and Kranton [18] and Fafchamps and Lund [19]) and the flow of bids or money in bipartite buyer-seller networks (see Kranton and Minehart $[20,21])$; for further examples of network applications, see Jackson [15]. Additionally, we employ stochastic stability in a network context as does Jackson and Watts [22, 23].

Lastly, we assume donations are divided among fundraisers in proportion to the time spent by the fund-raiser with the donor. Thus, our paper is related to the literature on productive rent-seeking games of Skaperdas [24] as well as to the literature on average surplus and average cost sharing games of Moulin [25], Moulin and Watts [26], and Watts [27]. (In fact, our model can be interpreted as a model where people have rights (or ties) to multiple common use resources. For instance, consider a group of fisherman where each fisherman has rights to fish on a subset of shared pools and must decide how much time to spend fishing on each pool given the decisions of the other fishermen.) The current paper differs from these previous papers in that the average surplus sharing or rent-seeking game is played on a network and each fund-raiser may solicit multiple donors.

The paper proceeds as follows. The basic model and monopoly fund-raiser results are presented in Sections 2 and 3. In Section 4, fund-raisers compete on the complete network. While the incomplete network results are presented in Section 5, and concluding remarks are presented in Section 6.

\section{Basic Model}

There are $N=\{1,2, \ldots, n\}$ potential donors. Let $M=$ $\{1,2, \ldots, m\}$ represent the set of fund-raisers. Each $i \in M$ has total time $T=1$ to spend asking for donations. Fundraiser $i$ can divide $T$ among the set $N$ where $t_{j}^{i}$ is the time $i$ spends with donor $j \in N$ to solicit his donation and $\sum_{j=1}^{n} t_{j}^{i} \leq 1$. Let $t^{i} \equiv\left\{t_{1}^{i}, t_{2}^{i}, \ldots, t_{n}^{i}\right\}, t_{j} \equiv\left\{t_{j}^{1}, t_{j}^{2}, \ldots, t_{j}^{m}\right\}$, and $t \equiv\left\{t^{1} ; t^{2} ; \ldots ; t^{m}\right\}$. Let $t^{-i} \equiv\left\{t^{1} ; t^{2} ; \ldots, t^{i-1}, t^{i+1}, \ldots, t^{m}\right\}$ and $t_{j}^{-i} \equiv\left\{t_{j}^{1}, t_{j}^{2}, \ldots t_{j}^{i-1}, t_{j}^{i+1}, \ldots, t_{j}^{m}\right\}$.

The profit $i \in M$ receives equals his donations net fundraising costs, where we assume a constant marginal cost of fund-raising equal to $c$. The donation $i$ receives from $j \in N$ depends on the time all fund-raisers spend with $j$ and is represented by $y\left(t_{j}^{i}, t_{j}^{-i}\right)$, while the profit $i$ receives from $j$ is represented by $\pi_{j}^{i}\left(t_{j}\right)=y\left(t_{j}^{i}, t_{j}^{-i}\right)-c t_{j}^{i}$. We assume $\partial y / \partial t_{j}^{i}>0$ and $y\left(0, t_{j}^{-i}\right)=0$. Additionally, we assume that if $\widetilde{t}_{j}^{-i}$ is any permutation of $t_{j}^{-i}$, then $y\left(t_{j}^{i} ; \widetilde{t}_{j}^{-i}\right)=y\left(t_{j}^{i} ; t_{j}^{-i}\right)$. Let the total profits that $i$ receives be represented by $\pi^{i}(t)=\sum_{j=1}^{n} \pi_{j}^{i}\left(t_{j}\right)$. For brevity, we will often abbreviate $\pi_{j}^{i}\left(t_{j}\right)$ by $\pi_{j}^{i}$ and $\pi^{i}(t)$ by $\pi^{i}$.

We assume that $c$ is small enough so that in all of the following results each fund-raiser will select $t^{i}$ such that $\sum_{j=1}^{n} t_{j}^{i}=1$. Thus, for simplicity we will ignore fund-raising costs in what follows.

\section{Monopoly Fund-Raiser}

As a benchmark, we first consider the case where there is no competition for donors by fund-raisers, or where $m=1$. We assume here that the monopoly fund-raiser has ties or links to all $n$ donors and thus that the fund-raiser donor network is complete. (Of course, if the fund-raiser were tied to less than $n$ donors, then the results below could easily be adjusted.)

The monopoly fund-raiser $i \in M$ wants to choose $t^{i}$ to maximize his total expected profits $\pi^{i}=\sum_{j=1}^{n} y\left(t_{j}^{i}\right)$. In the first proposition, we assume donor fatigue is present or that the donation function, $y$, is concave.

Proposition 1. Let $m=1$ and assume $y^{\prime \prime}<0$. Then $i \in M$ maximizes total expected profits by setting $t_{j}^{i}=1 / n$ for all $j \epsilon$ $N$.

Proof. As $y^{\prime}>0$, agent $i$ will always choose to use all of his time or to set $\sum_{j=1}^{n} t_{j}^{i}=1$. Agent $i$ wants to maximize $\pi^{i}$ or $\max _{t_{1}^{i}, \ldots, t_{n}^{i}} \sum_{j=1}^{n} y\left(t_{j}^{i}\right)$ subject to $\sum_{j=1}^{n} t_{j}^{i}=1$. First order conditions yield $y^{\prime}\left(t_{j}^{i}\right)=y^{\prime}\left(1-t_{1}^{i}-t_{2}^{i}-\cdots-t_{n}^{i}\right)$ for all $j \in\{1,2, \ldots, n-1\}$. Given $y^{\prime}>0$ and $y^{\prime \prime}<0$, these first order conditions are only met if $t_{1}^{i}=t_{2}^{i}=\cdots t_{n}^{i}$ or if $t_{j}^{i}=1 / n$ for all $j \in N$. Since $y^{\prime \prime}<0$, the corresponding bordered Hessian has leading principal minors which alternate in sign. Thus, $\pi^{i}$ is negative definite on $\sum_{j=1}^{n} t_{j}^{i}=1$ and our solution is a maximum.

In the second proposition, it is assumed that there is no donor fatigue or that the donation function is convex.

Proposition 2. Let $m=1$ and assume $y^{\prime \prime}>0$. Then $i \in M$ maximizes total expected profits by setting $t_{j}^{i}=1$ for some $j \epsilon$ $N$ and $t_{k}^{i}=0$ for all $k \neq j, k \in N$.

Proof. Agent $i$ wants to maximize $\pi^{i}$ or to $\max _{t_{1}^{i}, \ldots, t_{n}^{i}} \sum_{j=1}^{n} y\left(t_{j}^{i}\right)$ such that $\sum_{j=1}^{n} t_{j}^{i} \leq 1$. It is easy to check that given $y^{\prime}>0$ and 
$y^{\prime \prime}>0$, the solution to the maximization problem is a corner solution where $t_{j}^{i}=1$ for some $j \in N$.

\section{Fund-Raisers Competing on the Complete Network}

Next we consider the case where the number of fund-raisers $m>1$. In this section, we assume that each fund-raiser has access to every donor. If we consider a fund-raiser's access to a donor as a link between a fund-raiser and a donor, then every fund-raiser is linked to every donor and the fundraiser donor network is complete. The case of an incomplete network is considered in Section 5.

4.1. Average Donation Sharing Model on the Complete Network. Fund-raisers compete against each other in an average donation sharing game for each agent $j \in N$ 's donation. Fund-raisers simultaneously choose time spent with donors and if multiple fund-raisers solicit the same donor, then the donation is split among fund-raisers in proportion to the time spent with the donor. Formally, the donation $i \in M$ expects from $j \in N$ equals

$$
\pi_{j}^{i}=y\left(t_{j}^{i} ; t_{j}^{-i}\right)=\frac{t_{j}^{i}}{\sum_{k=1}^{m} t_{j}^{k}} f\left(\sum_{k=1}^{m} t_{j}^{k}\right)
$$

for some function $f$ such that $f(0)=0$ and $f^{\prime}>0$. Here, $f\left(\sum_{k=1}^{m} t_{j}^{k}\right)$ represents the total donations that donor $j$ will make given the total time all fund-raisers spend soliciting $j$ 's donation. For simplicity, we assume this function is the same for all donors. Additionally, note that we use the convention that if $t_{j}^{i}=0$ for all $i \in M$, then $\pi_{j}^{i}=0$.

We show next that allowing multiple fund-raisers to compete on the complete network generates results similar to those found in the monopoly fund-raiser case.

\subsection{Average Donation Sharing Results on the Complete Network}

Proposition 3. Let $m>1, f^{\prime \prime}<0$, and assume fundraisers compete in an average donation sharing game. At the symmetric Nash equilibrium of the average donation sharing game, $t_{j}^{i}=1 / n$ for all $j \in N$ and $i \in M$.

Proof. We find $i \in M$ 's best response to $t_{j}^{k}=1 / n$ for all $k \neq i$, $k \in M$, and $j \in N$. Since $\pi_{j}^{i}=\left(t_{j}^{i} / \sum_{k=1}^{m} t_{j}^{k}\right) f\left(\sum_{k=1}^{m} t_{j}^{k}\right)$ we know that $\pi^{i}=\sum_{j=1}^{n}\left(\left(t_{j}^{i} / \sum_{k=1}^{m} t_{j}^{k}\right) f\left(\sum_{k=1}^{m} t_{j}^{k}\right)\right)$. Thus $i$ 's maximization problem is

$$
\begin{gathered}
\max _{t_{i}^{i}, t_{2}^{i}, \ldots, t_{n}^{i}} \pi^{i} \\
\text { such that } \\
\sum_{j=1}^{n} t_{j}^{i}=1
\end{gathered}
$$

with Lagrangian $\mathscr{L}^{i}=\pi^{i}-\lambda\left(\sum_{j=1}^{n} t_{j}^{i}-1\right)$ and first order conditions

$$
\begin{aligned}
\frac{\partial \mathscr{L}^{i}}{\partial t_{j}^{i}}= & \left(\frac{\sum_{k \neq i} t_{j}^{k}}{\left(t_{j}^{i}+\sum_{k \neq i} t_{j}^{k}\right)^{2}}\right) f\left(t_{j}^{i}+\sum_{k \neq i} t_{j}^{k}\right) \\
& +\left(\frac{t_{j}^{i}}{\left(t_{j}^{i}+\sum_{k \neq i} t_{j}^{k}\right)}\right) f^{\prime}\left(t_{j}^{i}+\sum_{k \neq i} t_{j}^{k}\right) \\
& -\lambda=0 \quad \forall j \in N, \\
& \frac{\partial \mathscr{L}^{i}}{\partial \lambda}=-\sum_{j=1}^{n} t_{j}^{i}+1=0 .
\end{aligned}
$$

If $t_{j}^{k}=1 / n$ for all $k \neq i, k \in M$, and $j \in N$, then $\sum_{k \neq i} t_{j}^{k}=$ $(m-1) / n$ for all $j \in N$ and the solution to the above first order conditions is $t_{j}^{i}=1 / n$ for all $j \in N$. To check the second order conditions, let $O_{j}^{i}((m-1) / n)=p\left(t_{j}^{i} /\left(t_{j}^{i}+(m-1) / n\right)\right) f\left(t_{j}^{i}+\right.$ $(m-1) / n)$ represent $i$ 's opportunity set for donations from $j$ given $t_{j}^{k}=1 / n$ for all $k \neq i, k \in M$. Thus, $\pi^{i}\left(t^{i},(m-1) / n\right)=$ $\sum_{j=1}^{n} O_{j}^{i}((m-1) / n)$. It is easy to check that $\partial O_{j}^{i} / \partial t_{j}^{i}>0$ and $\partial^{2} O_{j}^{i} / \partial\left(t_{j}^{i}\right)^{2}<0$ for all $0<t_{j}^{i} \leq 1$. Thus, $\pi^{i}\left(t^{i},(m-1) / n\right)$ is negative definite on $\sum_{j=1}^{n} t_{j}^{i}=1$. So $t_{j}^{i}=1 / n$ for all $j \in N$ is $i$ 's best response to $t_{j}^{k}=1 / n$ for all $k \neq i, k \in M$, and $j \in N$, and our solution is a Nash equilibrium.

Note that we focus on only the symmetric Nash equilibrium in this proposition and in the first part of Section 5 where the donation function is concave. The reason is threefold. First, we want to compare the Nash equilibria of the game played on the complete network to the game played on the incomplete network. Concentrating on the symmetric Nash in each situation facilitates this comparison. Second, focusing on the symmetric Nash simplifies our calculations. The first order conditions of our maximization problem are quite complex making it extremely difficult to compute other possible equilibria. Lastly, we hypothesize that in many cases the symmetric Nash is the unique Nash, although proving this is quite difficult and is beyond the scope of the current paper.

Proposition 4. Let $m>1, f^{\prime \prime}>0$, and assume fund-raisers compete in an average donation sharing game. At all Nash equilibria there exists $k \in N$ such that $t_{k}^{i}=1$ for all $i \in M$.

Proof. Assume that there exists $k \in N$ such that $t_{k}^{\ell}=1$ for all $\ell \neq i, \ell \in M$. We find $i \in M$ 's best response. Here, $\pi^{i}=$ $\sum_{j \in N, j \neq k}\left(t_{j}^{i} /\left(t_{j}^{i}\right)\right) f\left(t_{j}^{i}\right)+\left(t_{k}^{i} /\left(t_{k}^{i}+(m-1)\right)\right) f\left(t_{k}^{i}+(m-1)\right)$ with $\sum_{j=1}^{n} t_{j}^{i}=1$. Since $f^{\prime}>0$ and $f^{\prime \prime}>0, i$ does best by choosing $t_{k}^{i}=1$ and $t_{j}^{i}=0$ for all $j \in N, j \neq k$. Next we show that all Nash equilibria are of this type. Consider $i$ 's best response to a fixed $t^{-i}$. Here $i$ 's best response is to set $t_{k}^{i}=1$ for some $k$ such that $k \in \arg \max _{j} \sum_{\ell \in M, \ell \neq i} t_{j}^{\ell}$. Given that this is true for all $i \in M$, all Nash equilibria must be as described. 


\section{Competition on an Incomplete Network}

Let $g$ represent a network of connections between fundraisers and donors. If $i \in M$ and $j \in N$, then $i j \in g$ if $i$ and $j$ are linked. Note that for all links, $i j$, we will use the convention that the fund-raiser is always listed first.

Let $B(j, g)=\{i \mid i j \in g, i \in M\}$; thus, $B(j, g)$ represents the set of fund-raisers that $j \in N$ is directly linked with in graph $g$. Let $|S|$ represent the cardinality of set $S \subset \mathbb{Z}$. Let $A_{z}(i, g)=\{j \mid i j \in g, j \in N$ and $|B(j, g)|=z\}$; thus, $A_{z}(i, g)$ represents the set of donors that $i$ is linked to in $g$ such that each donor in the set has exactly $z$ direct links.

Let fund-raisers compete in an average donation sharing game and assume $g$ is fixed. Here

$$
\begin{gathered}
\pi^{i}=\sum_{j \in A_{1}(i, g)} f\left(t_{j}^{i}\right)+\sum_{j \in A_{2}(i, g)} \frac{t_{j}^{i}}{t_{j}^{i}+t_{j}^{k(j)}} f\left(t_{j}^{i}+t_{j}^{k(j)}\right) \\
+\cdots+\sum_{j \in A_{m}(i, g)} \frac{t_{j}^{i}}{\sum_{\ell=1}^{m} t_{j}^{\ell}} f\left(\sum_{\ell=1}^{m} t_{j}^{\ell}\right),
\end{gathered}
$$

where $k(j) \in M$ such that $k j \in g$.

5.1. Competition on an Incomplete Network with Donor Fatigue. In this section, donor fatigue is present or the donation function is assumed to be concave. Thus, every unit of time a fund-raiser spends with a donor increases his total donation less than does the previous unit of time.

The following example illustrates how the results for the incomplete network are quite different from those found for the complete network. The example shows that time spent soliciting donations depends on both the network configuration and on the degree of donor fatigue or on the curvature of $f(t)$.

Example 5 (Illustrating the effects of severe versus mild donor fatigue). Let $M=\{1,2\}$ and $N=\{1,2,3\}$. Let $f(t)=t^{1 / 2}$. Let $g_{1}=\{11,12,21,22\}$ and $g_{2}=\{11,12,22,23\}$. Notice that in network $g_{1}$ each fund-raiser is tied to the same two donors. In network $g_{2}$ each fund-raiser again has two ties, but this time only one donor is common to both fund-raisers while each fund-raiser also has one tie to a donor that the other has no ties to. By Proposition 3, the symmetric Nash equilibrium of the average donation sharing game with network $g_{1}$ is $t_{j}^{i}=1 / 2$ for all $i \in M, j \in N$. Next, we consider the symmetric Nash equilibrium of the average donation sharing game with network $g_{2}$. Here $\pi^{1}=\left(t_{1}^{1}\right)^{1 / 2}+\left(t_{2}^{1} /\left(t_{2}^{1}+t_{2}^{2}\right)\right)\left(t_{2}^{1}+t_{2}^{2}\right)^{1 / 2}$ and $\pi^{2}$ is similar. First order conditions for fund-raiser 1 yield $(1 / 2)\left(t_{1}^{1}\right)^{-1 / 2}=\left(t_{2}^{2} /\left(t_{2}^{1}+t_{2}^{2}\right)^{2}\right)\left(t_{2}^{1}+t_{2}^{2}\right)^{1 / 2}+\left((1 / 2) t_{2}^{1} /\left(t_{2}^{1}+t_{2}^{2}\right)\right)\left(t_{2}^{1}+\right.$ $\left.t_{2}^{2}\right)^{-1 / 2}$ and $t_{1}^{1}+t_{2}^{1}=1$, with fund-raiser 2 having similar first order conditions. At the symmetric Nash equilibrium $t_{1}^{1}=t_{3}^{2}=.47$ and $t_{2}^{1}=t_{2}^{2}=.53$. Thus, if donor fatigue is severe or if the donation function is fairly curved, then fund-raisers spend more time with the shared donor than they do in network $g_{1}$ and less time with the unshared donor. However, if we decrease the level of donor fatigue or change $f(t)$ so that $f(t)=t^{7}$, then at the symmetric Nash of the game with $g_{2}, t_{1}^{1}=t_{3}^{2}=.502$ and $t_{2}^{1}=t_{2}^{2}=.498$. Now fund-raisers spend less time with the shared donor and more time with the unshared donor.

Next, we generalize the mild versus severe donor fatigue results of these examples. Consider the general case of any concave donation function, $f$, and compare two symmetric networks: one where all fund-raisers are linked to the same set of donors, and one where each fund-raiser has the same number of un-shared ties and has the same set of shared ties.

Specifically, let $M=\{1,2\}$ and $N=\{1,2, \ldots, 2 a+b\}$ for $a, b \in \mathbb{Z}, a \geq 1$ and $b \geq 1$. Let $g^{(a+b)}=\{11,12, \ldots, 1(a+$ $b), 21,22, \ldots, 2(a+b)\}$. Here each donor has $(a+b)$ shared links. Let $g^{a, b}=\{11,12, \ldots, 1(a+b), 2(a+1), 2(a+$ $2), \ldots, 2(2 a+b)\}$. Here each donor has $a$ un-shared ties and $b$ shared ties.

Proposition 6. Let $m=2$ and $n=2 a+b$. At the symmetric Nash equilibrium of the average donation sharing game with $g^{(a+b)}, t_{j}^{i}=1 /(a+b)$ for all $j \in N, i \in M$. At the symmetric Nash equilibrium of the average donation sharing game with $g^{a, b}$

(1) if $f^{\prime}(t)<f(2 t) / 4 t+f^{\prime}(2 t) / 2$ for all $0 \leq t \leq m$, then

(a) $t_{j}^{i}<1 /(a+b)$ for all $i \in M$ and $j \in\{1,2, \ldots, a, a+$ $b+1, a+b+2, \ldots, 2 a+b\}$ and

(b) $t_{j}^{i}>1 /(a+b)$ for all $i \in M$ and $j \in\{a+1, a+$ $2, \ldots, a+b\}$, and

(2) if $f^{\prime}(t)>f(2 t) / 4 t+f^{\prime}(2 t) / 2$ for all $0 \leq t \leq m$, then

(a) $t_{j}^{i}>1 /(a+b)$ for all $i \in M$ and $j \in\{1,2, \ldots, a, a+$ $b+1, a+b+2, \ldots, 2 a+b\}$ and

(b) $t_{j}^{i}<1 /(a+b)$ for all $i \in M$ and $j \in\{a+1, a+$ $2, \ldots, a+b\}$.

Proof. The statement regarding the symmetric Nash equilibrium for the game with $g^{(a+b)}$ is proven true by Proposition 3 . Next we find the symmetric Nash equilibrium for the average donation sharing game with $g^{a, b}$. Here $\pi^{1}=\sum_{j=1}^{a} f\left(t_{j}^{1}\right)+$ $\sum_{k=a+1}^{a+b}\left(t_{k}^{1} /\left(t_{k}^{1}+t_{k}^{2}\right)\right) f\left(t_{k}^{1}+t_{k}^{2}\right)$ while $\pi^{2}$ is similar. The first order conditions for the Nash equilibrium require that $f^{\prime}\left(t_{j}^{1}\right)=$ $\left(t_{k}^{2} /\left(t_{k}^{1}+t_{k}^{2}\right)^{2}\right) f\left(t_{k}^{1}+t_{k}^{2}\right)+\left(t_{k}^{1} /\left(t_{k}^{1}+t_{k}^{2}\right)\right) f^{\prime}\left(t_{k}^{1}+t_{k}^{2}\right)$ for all $j \epsilon$ $\{1,2, \ldots, a\}$ and $k \in\{a+1, a+2, \ldots, a+b\}$. At the symmetric Nash equilibrium, $t_{1} \equiv t_{j}^{1}=t_{\ell}^{2}$ for all $j \in\{1,2, \ldots, a\}$ and $\ell \in\{a+b+1, a+b+2, \ldots, 2 a+b\}$ and $t_{a+1} \equiv t_{k}^{1}=t_{k}^{2}$ for all $k \in\{a+1, a+2, \ldots, a+b\}$. In addition we know that $\sum_{j=1}^{a+b} t_{j}^{1}=1$. Thus, we can rewrite the first order conditions as

$$
\begin{aligned}
f^{\prime}\left(t_{1}\right)= & \frac{t_{a+1}}{\left(2 t_{a+1}\right)^{2}} f\left(2 t_{a+1}\right) \\
& +\frac{t_{a+1}}{2 t_{a+1}} f^{\prime}\left(2 t_{a+1}\right) \quad \text { where } a t_{1}+b t_{a+1}=1 .
\end{aligned}
$$

If to the contrary we let $t_{1}=t_{a+1}=1 /(a+b)$, then the first order conditions simplify to $f^{\prime}(1 /(a+b))=(1 / 2)(f(2 /(a+$ $b)) /(2 /(a+b)))+(1 / 2) f^{\prime}(2 /(a+b))$. If $f^{\prime}(t)<f(2 t) / 4 t+$ $f^{\prime}(2 t) / 2$ for all $0 \leq t \leq m$, then our first order condition 
will not be met. Fund-raiser 1 must increase the left hand side of (5) and decrease the right hand side. Since $f^{\prime}>0$ and $f^{\prime \prime}<0$, we know that $t_{1}$ must be decreased and thus $t_{a+b}$ increased. Thus, at the Nash equilibrium $t_{1}<1 /(a+b)$ and $t_{a+1}>1 /(a+b)$. If instead $f^{\prime}(t)>f(2 t) / 4 t+f^{\prime}(2 t) / 2$ for all $0 \leq t \leq m$, then in order to meet (5) we must increase $t_{1}$ and so at the Nash $t_{1}>1 /(a+b)$ and $t_{a+1}<1 /(a+b)$.

Notice that our condition $f^{\prime}(t)<f(2 t) / 4 t+f^{\prime}(2 t) / 2$ and our assumptions $f^{\prime}>0, f^{\prime \prime}<0$, and $f(0)=0$ together imply that $f(t) / t$ is significantly larger than $f^{\prime}(t)$ which is true when $f$ is fairly curved. For the function $f(t)=t^{\alpha}$, the condition $f^{\prime}(t)<f(2 t) / 4 t+f^{\prime}(2 t) / 2$ is met when $0<\alpha \leq .63$, while the condition $f^{\prime}(t)>f(2 t) / 4 t+f^{\prime}(2 t) / 2$ is met when $f(t)=t^{\alpha}$ for $.64 \leq \alpha<1$.

Proposition 6 says that if donor fatigue is severe or if the donation function, $f(t)$, is fairly curved, then fund-raisers spend more time with shared ties and less time with unshared ties. While if donor fatigue is mild or if the donation function is straighter, then fund-raisers spend more time with un-shared donors and less time with shared donors. Intuitively, if donor fatigue is severe, then when a fund-raiser spends more time with a donor, the donor's total donation does not increase much. Thus, the benefit from increasing time spent with an un-shared donor tie is not very large. However, if a fund-raiser spends more time with a shared donor tie, then although this donor's total donation may not increase much the fund-raiser's share of this donation does increase. Thus, it is worthwhile for the fund-raiser to increase time spent with shared ties in order to steal donations from other fund-raisers. If donor fatigue is mild, then as the fundraiser increases the time spent with a donor, his total donation increases more than in the severe donor fatigue case making it worthwhile for the fund-raiser to spend extra time with unshared donors.

Next we consider an example with extreme donor fatigue and compare three networks; in all three networks each fundraiser is tied to $z \in \mathbb{Z}^{+}$donors. In the first network, $g^{z}$, all fund-raisers are linked to the same set of donors. In network $g^{z-1,1}$, each fund-raiser has only one shared tie and $(z-1)$ unshared ties. In $g^{1, z-1}$, each fund-raiser has only one un-shared tie and $(z-1)$ shared ties.

Example 7 (Severe donor fatigue and the number of shared ties). Let $M=\{1,2\}$ and $N=\{1,2,3, \ldots, 2 z-1\}$ for $z \geq 2$ and $z \in \mathbb{Z}$. Let $f(t)=t^{1 / 2}$. Let $g^{z}=\{11,12, \ldots, 1 z, 21,22, \ldots, 2 z\}$, $g^{z-1,1}=\{11,12, \ldots, 1 z, 2 z, 2(z+1), \ldots, 2(2 z-1)\}$, and $g^{1, z-1}=\{11,12, \ldots, 1 z, 22,23, \ldots, 2(z+1)\}$. By Proposition 3 , the symmetric Nash equilibrium of the average donation sharing game with network $g^{z}$ is $t_{j}^{i}=1 / z$ for all $i \in M, j \in N$. For $g^{z-1,1}$ at the symmetric Nash $t_{k}^{1}=t_{j}^{2}=1 /(z+.125)$ for $k \in\{1, \ldots, z-1\}, j \in\{z+1, \ldots, 2 z-1\}$ and $t_{z}^{1}=t_{z}^{2}=$ $1.125 /(z+.125)$. While at the symmetric Nash for $g^{1, z-1}, t_{1}^{1}=$ $t_{z+1}^{2}=1 /(1.125 z-.125)$ and $t_{k}^{1}=t_{j}^{2}=1.125 /(1.125 z-.125)$ for $k, j \in\{2, \ldots, z\}$. Again if donor fatigue is severe, then the fund-raisers spend more time with the shared donors and less time with the un-shared donors. Notice that fundraisers spend more time per link with both un-shared and shared links in the network with fewer shared ties $\left(g^{z-1,1}\right)$ than in $g^{1, z-1}$, but the ratio of time spent with un-shared to shared links $\left(t_{1}^{1} / t_{z}^{1}\right)$ is the same for these two networks. Thus, as the number of shared ties increases, a fund-raiser's time per donor decreases since a fund-raiser with severe donor fatigue now has more of the time-consuming shared ties.

Next we generalize the results of Proposition 6 to the case of $m \geq 2$ fund-raisers. Let there be $m$ fund-raisers and $n$ donors. Let $g^{\text {sym }}$ be a symmetric network such that each fundraiser has $a_{1}$ ties to donors shared with no one, $a_{2}$ ties to donors shared with one other fund-raiser, $a_{3}$ ties to donors shared with two other fund-raisers,..., and $a_{m}$ ties to donors shared with all other fund-raisers, where $a_{k} \in \mathbb{Z}_{+}$for all $k \in$ $\{1,2, \ldots, m\}$. Let $g^{C}$, be a complete network where each fundraiser is tied to each $j \in\left\{1,2, \ldots, \sum_{i=1}^{m} a_{i}\right\}$ and $j \in N$. Note that in network $g^{C}$ each fund-raiser has the same number of links as he does in $g^{\text {sym }}$.

At the symmetric Nash equilibrium of the average donation sharing game with any $g^{\text {sym }}$ we define $t_{\alpha_{k}}$ as the time $i \in M$ spends with each of his $a_{k}$ ties.

Proposition 8. If $((k-1) / k)(f(k t) / k t)+(1 / k) f^{\prime}(k t)>(k /(k+$ 1)) $(f((k+1) t) /(k+1) t)+(1 /(k+1)) f^{\prime}((k+1) t)$ for all $0 \leq t \leq 1$ and $k \in\{1,2, \ldots, m-1\}$, then at the symmetric Nash equilibrium of the average donation sharing game with any $g^{\text {sym }}, t_{\alpha_{k}}>t_{\alpha_{k+1}}$. At the symmetric Nash equilibrium of the game with $g^{C}, t_{j}^{i}=1 / \sum_{\ell=1}^{m} a_{\ell}$ for all $i \in M, j \in N$.

Thus, Proposition 8 says that if donor fatigue is mild, then fund-raisers spend the most time soliciting donors that they are the only fund-raiser tied to and the least time soliciting donors that all fund-raisers are tied to.

Essentially the condition $((k-1) / k)(f(k t) / k t)+$ $(1 / k) f^{\prime}(k t)>(k /(k+1))(f((k+1) t) /(k+1) t)+(1 /(k+$ 1)) $f^{\prime}((k+1) t)$ requires that $f((k+1) t) /(k+1) t$ is not too big or that the average of $f$ is not too much bigger than the slope of $f$. If $f(t)=t^{\beta}$, then the condition $((k-1) / k)(f(k t) / k t)+(1 / k) f^{\prime}(k t)>(k /(k+1))$ $(f((k+1) t) /(k+1) t)+(1 /(k+1)) f^{\prime}((k+1) t)$ is equivalent to requiring $((k-1+\beta) /(k+\beta))>((k+1) / k)^{\beta-2}$ and is true for all $.64 \leq \beta<1$ but does not hold true for $0<\beta \leq .63$.

Proof. The results regarding the complete network $g^{C}$ are proved true by Proposition 3. Consider any fixed network $g^{\text {sym }}$. Let $A_{j} \subseteq N$ represent the set of donors each having $j$ ties in $g^{\text {sym }}, j \in\{1,2, \ldots, m\}$. Thus, $A_{j}=\cup_{i=1}^{m} A_{j}\left(i, g^{\text {sym }}\right)$. Let $\alpha_{j} \in A_{j}$ represent an element of this set. Profits for fundraiser 1 are represented as

$$
\begin{aligned}
\pi^{1}= & \sum_{\alpha_{1} \in A_{1} ; 1 \alpha_{1} \in g^{\text {sym }}} f\left(t_{\alpha_{1}}^{1}\right) \\
& +\sum_{\alpha_{2} \in A_{2} ; 1 \alpha_{2} \in g^{\mathrm{sym}}, \ell \alpha_{2} \in g^{\mathrm{sym}}} \frac{t_{\alpha_{2}}^{1}}{t_{\alpha_{2}}^{1}+t_{\alpha_{2}}^{\ell}} f\left(t_{\alpha_{2}}^{1}+t_{\alpha_{2}}^{\ell}\right) \\
& +\cdots+\sum_{\alpha_{m} \in A_{m} ; 1 \alpha_{m} \in g^{\mathrm{sym}}} \frac{t_{\alpha_{m}}^{1}}{\sum_{i=1}^{m} t_{\alpha_{m}}^{i}} f\left(\sum_{i=1}^{m} t_{\alpha_{m}}^{i}\right)
\end{aligned}
$$


with $\ell \in M$ and $\ell \neq 1$. First order conditions require

$$
\begin{aligned}
f^{\prime}\left(t_{\alpha_{1}}^{1}\right)= & \frac{t_{\alpha_{2}}^{\ell}}{\left(t_{\alpha_{2}}^{1}+t_{\alpha_{2}}^{\ell}\right)^{2}} f\left(t_{\alpha_{2}}^{1}+t_{\alpha_{2}}^{\ell}\right) \\
& +\frac{t_{\alpha_{2}}^{1}}{t_{\alpha_{2}}^{1}+t_{\alpha_{2}}^{\ell}} f^{\prime}\left(t_{\alpha_{2}}^{1}+t_{\alpha_{2}}^{\ell}\right)=\cdots \\
= & \frac{t_{\alpha_{m}}^{2}+t_{\alpha_{m}}^{3}+\cdots+t_{\alpha_{m}}^{m}}{\left(t_{\alpha_{n}}^{1}+t_{\alpha_{n}}^{2}+\cdots+t_{\alpha_{n}}^{n}\right)^{2}} f\left(t_{\alpha_{m}}^{1}+t_{\alpha_{m}}^{2}+\cdots+t_{\alpha_{m}}^{m}\right) \\
& +\frac{t_{\alpha_{m}}^{1}}{t_{\alpha_{m}}^{1}+t_{\alpha_{m}}^{2}+\cdots+t_{\alpha_{m}}^{m}} f^{\prime}\left(t_{\alpha_{m}}^{1}+t_{\alpha_{m}}^{2}+\cdots+t_{\alpha_{m}}^{m}\right)
\end{aligned}
$$

and $\sum_{j=1}^{m} a_{j} t_{\alpha_{j}}^{1}=1$, where $\alpha_{i} \in A_{i}, 1 \alpha_{i} \in g^{\text {sym }}, \ell \alpha_{i} \in g^{\text {sym }}$ for $i \in\{1,2, \ldots, m\}, \ell \neq 1, \ell \in M$. The first order conditions for $i \neq 1, i \in M$ are similar.

At the symmetric Nash equilibrium $t_{\alpha_{j}} \equiv t_{\alpha_{j}}^{i}=t_{\alpha_{j}}^{\ell}$ for all $i \neq \ell, i, \ell \in M, \alpha_{j} \in A_{j}, i \alpha_{j} \in g^{\text {sym }}, \ell \alpha_{j} \in g^{\text {sym }}$ and $j \in$ $\{1,2, \ldots, m\}$. We can rewrite the first order conditions as

$$
\begin{aligned}
f^{\prime}\left(t_{\alpha_{1}}\right) & =\frac{1}{4 t_{\alpha_{2}}} f\left(2 t_{\alpha_{2}}\right)+\frac{1}{2} f^{\prime}\left(2 t_{\alpha_{2}}\right) \\
& =\frac{2}{9 t_{\alpha_{3}}} f\left(3 t_{\alpha_{3}}\right)+\frac{1}{3} f^{\prime}\left(3 t_{\alpha_{3}}\right)=\cdots \\
& =\frac{(m-1)}{m^{2} t_{\alpha_{m}}} f\left(m t_{\alpha_{m}}\right)+\frac{1}{m} f^{\prime}\left(m t_{\alpha_{m}}\right),
\end{aligned}
$$

where $\sum_{j=1}^{m} a_{j} t_{\alpha_{j}}=1$.

Assume to the contrary that $t_{\alpha_{k}}=1 / \sum_{j=1}^{m} a_{j} \equiv \bar{t}$ for all $k \in\{1,2, \ldots, m\}$. Then, by assumption

$$
\begin{aligned}
f^{\prime}(\bar{t}) & >\frac{1}{2} \frac{f(2 \bar{t})}{2 \bar{t}}+\frac{1}{2} f^{\prime}(2 \bar{t})>\frac{2}{3} \frac{f(3 \bar{t})}{3 \bar{t}}+\frac{1}{3} f^{\prime}(3 \bar{t}) \\
& >\cdots>\frac{(m-1)}{m} \frac{f(m \bar{t})}{m \bar{t}}+\frac{1}{m} f^{\prime}(m \bar{t})
\end{aligned}
$$

and the first order conditions are not met. In order to meet the first order conditions, we must decrease $f^{\prime}\left(t_{\alpha_{1}}\right)$ in comparison to $\left(1 / 4 t_{\alpha_{2}}\right) f\left(2 t_{\alpha_{2}}\right)+(1 / 2) f^{\prime}\left(2 t_{\alpha_{2}}\right)$ and decrease $\left(1 / 4 t_{\alpha_{2}}\right) f\left(2 t_{\alpha_{2}}\right)+(1 / 2) f^{\prime}\left(2 t_{\alpha_{2}}\right)$ in comparison to $\left(2 / 9 t_{\alpha_{3}}\right) f\left(3 t_{\alpha_{3}}\right)+(1 / 3) f^{\prime}\left(3 t_{\alpha_{3}}\right)$, and so forth. Since $f^{\prime}>0$, $f^{\prime \prime}<0$, we know that $t_{\alpha_{i}}$ must be increased in comparison to $t_{\alpha_{i+1}}$ for all $i \in\{1,2, \ldots, m-1\}$. Thus, in equilibrium $t_{\alpha_{1}}>t_{\alpha_{2}}>\cdots>t_{\alpha_{m}}$.

Proposition 9. If $f^{\prime}(t)<((k-1) / k)(f(k t) / k t)+(1 / k) f^{\prime}(k t)$ for $k \in\{2,3, \ldots, m\}$, then at the symmetric Nash equilibrium of the average donation sharing game with any $g^{\text {sym }}, t_{\alpha_{k}}>t_{\alpha_{1}}$.

Corollary 10. If $f^{\prime}(t)<(1 / 2)(f(2 t) / 2 t)+(1 / 2) f^{\prime}(2 t)$, then at the symmetric Nash equilibrium of the average donation sharing game with any $g^{\text {sym }}, t_{\alpha_{2}}<t_{\alpha_{1}}$.
Proof. The following is a proof of Corollary 10 as the proof of Proposition 9 is similar. Profits for fund-raiser 1 are as given by (6) and first order conditions are as given by (7). Thus, in equilibrium we must have $f^{\prime}\left(t_{\alpha_{1}}^{1}\right)=\left(t_{\alpha_{2}}^{j} /\left(t_{\alpha_{2}}^{1}+\right.\right.$ $\left.\left.t_{\alpha_{2}}^{j}\right)^{2}\right) f\left(t_{\alpha_{2}}^{1}+t_{\alpha_{2}}^{j}\right)+\left(t_{\alpha_{2}}^{1} /\left(t_{\alpha_{2}}^{1}+t_{\alpha_{2}}^{j}\right)\right) f^{\prime}\left(t_{\alpha_{2}}^{1}+t_{\alpha_{2}}^{j}\right)$ for $\alpha_{1} \in A_{1}$, $\alpha_{2} \in A_{2}, 1 \alpha_{1} \in g^{\mathrm{sym}}, j \alpha_{2} \in g^{\mathrm{sym}}, j \neq 1$, and $j \in M$. Assume to the contrary that $t_{\alpha_{1}}=t_{\alpha_{2}}=\bar{t}$. Then, by assumption $f^{\prime}(\bar{t})<(1 / 2)(f(2 \bar{t}) / 2 \bar{t})+(1 / 2) f^{\prime}(2 \bar{t})$. In order to meet our first order conditions, we must increase the left hand side of this inequality and decrease the right hand side. Since $f^{\prime}>0$ and $f^{\prime \prime}<0$, this requires that we decrease $t_{\alpha_{1}}$ and increase $t_{\alpha_{2}}$ and so in equilibrium $t_{\alpha_{1}}<t_{\alpha_{2}}$.

Proposition 9 says that if donor fatigue is severe, then fund-raisers spend more time soliciting donors that at least one other fund-raiser is also tied to over donors that they are the only fund-raiser tied to. We additionally provide Corollary 10 as it is fairly easy to meet the conditions of Proposition 9 for $k=2$, but as $k$ increases the conditions are only met as donor fatigue becomes more severe. For instance if $f(t)=t^{\beta}$ and $k=2$, then the conditions of Proposition 9 are met for $0<\beta \leq .63$. For $k=3$, the conditions are met if $0<\beta \leq .43$ and if $k=10$, the conditions are met if $0<\beta \leq .12$. (We stop our calculations at $k=10$ as $k$ represents the number of fund-raisers who are tied to a particular donor and in a fund-raising network one would expect for this number not to be too large.) Thus, if donor fatigue is severe enough, then $t_{\alpha_{1}}$ is the smallest $t_{\alpha_{k}}$ for $k \epsilon$ $\{1,2, \ldots, m\}$. As the following example illustrates if donor fatigue is not as severe it is possible for $t_{\alpha_{1}}<t_{\alpha_{2}}$ but $t_{\alpha_{1}}>t_{\alpha_{3}}$.

Example 11 (Donor fatigue and the relationship between $t_{\alpha_{1}}$, $t_{\alpha_{2}}$, and $t_{\alpha_{3}}$ ). Let $M=\{1,2,3\}$ and $N=\{1,2,3,4,5,6,7\}$. Let $g_{1}=\{11,12,13,14,21,22,23,24,31,32,33,34\}$ and let $g_{2}=\{11,12,13,14,22,24,25,26,33,34,35,37\}$. A graph of $g_{2}$ is provided in Figure 1. In network $g_{2}$ each fund-raiser has one tie to an un-shared donor, two ties to donors shared with one other fund-raiser, and one tie to donor 4 , while in network $g_{1}$ all fund-raisers are tied to the same set of four donors. By Proposition 3, the symmetric Nash equilibrium of the average donation sharing game with network $g_{1}$ is $t_{j}^{i}=1 / 4$ for all $i \in M, j \in N$. Next we consider the symmetric Nash equilibrium of the game with network $g_{2}$. Here $\pi^{1}=$ $f\left(t_{1}^{1}\right)+\sum_{j \in\{2,3\}}\left(t_{j}^{1} /\left(t_{j}^{1}+t_{j}^{j}\right)\right) f\left(t_{j}^{1}+t_{j}^{j}\right)+\left(t_{4}^{1} /\left(t_{4}^{1}+t_{4}^{2}+t_{4}^{3}\right)\right) f\left(t_{4}^{1}+\right.$ $\left.t_{4}^{2}+t_{4}^{3}\right)$ and $\pi^{2}$ and $\pi^{3}$ are similar. First we consider a case of extreme donor fatigue. Let $f(t)=t^{.5}$; then at the symmetric Nash equilibrium $t_{1}^{1}=t_{6}^{2}=t_{7}^{3}=.24, t_{j}^{i}=.27$, and $t_{4}^{i}=.22$ for $i \in M, j \in\{2,3,5\}$. Thus, $t_{\alpha_{2}}>t_{\alpha_{1}}>t_{\alpha_{3}}$ or the tie to donor 4 who is tied to all fund-raisers is weighted least while the ties to donors shared among two fund-raisers are weighted most. Next we allow the extreme donor fatigue to be more severe. Let $f(t)=t^{1}$, then at the symmetric Nash equilibrium $t_{1}^{1}=t_{6}^{2}=t_{7}^{3}=.09, t_{j}^{i}=.32$, and $t_{4}^{i}=.27$ for $i \in M$, $j \in\{2,3,5\}$. Here $t_{\alpha_{2}}>t_{\alpha_{3}}>t_{\alpha_{1}}$ and the tie to the donor shared with no one is weighted least while the ties to donors shared among two fund-raisers are weighted most. Finally, we 


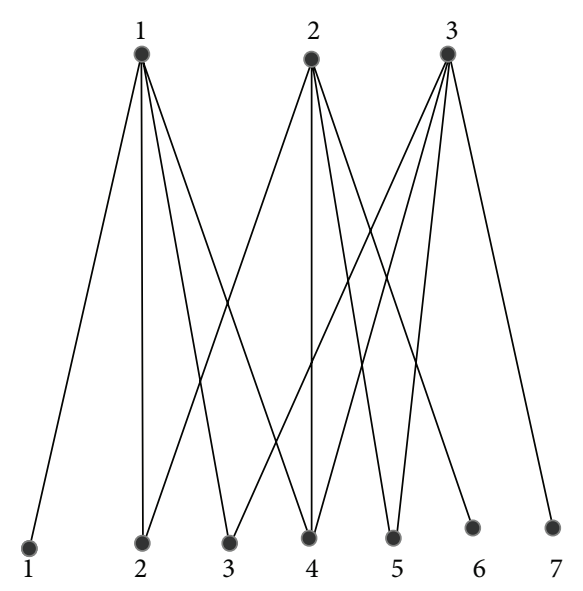

Figure 1: Fund-raisers $\{1,2,3\}$ are on top and donors $\{1,2,3$, $4,5,6,7\}$ are on bottom.

consider a case of mild donor fatigue. Let $f(t)=t^{9}$, then at the symmetric Nash equilibrium $t_{1}^{1}=t_{6}^{2}=t_{7}^{3}=.29, t_{j}^{i}=.25$, and $t_{4}^{i}=.20$ for $i \in M, j \in\{2,3,5\}$. Just as predicted in Proposition 8, $t_{\alpha_{1}}>t_{\alpha_{2}}>t_{\alpha_{3}}$ and the tie to donor 4 who is tied to all fund-raisers is weighted least while the tie to the donor shared with no one is weighted most.

5.2. Competition on an Incomplete Network with No Donor Fatigue. Next we consider a case of no donor fatigue where the donation function is convex or where all of the time spent with a donor significantly increases donations. Here agents want to spend time with donors that others are soliciting. However, the network may not allow all fund-raisers to solicit a popular donor; this can create multiple equilibria where several donors are solicited at the same time as can be seen in the following example.

Example 12 (Multiple equilibria with no donor fatigue). Let $M=\{1,2,3\}$ and $N=\{1,2,3,4,5,6,7\}$. Let $f^{\prime}>0$ and $f^{\prime \prime}>0$. Let $g=\{11,12,13,14,22,24,25,26,33,34,35,37\}$. A graph of $g$ is provided in Figure 1. Each fund-raiser has one tie to a donor untied to other fund-raisers, two ties to donors shared with one other fund-raiser, and one tie to a donor (donor 4) shared with all fund-raisers. As $f^{\prime}>0$ and $f^{\prime \prime}>0$, each fund-raiser wants to solicit only one donor and prefers to solicit a donor who is already being solicited by others. In this example, there are 14 pure Nash equilibrium: (1) $t_{1}^{1}=t_{6}^{2}=t_{7}^{3}=1$, all other $t_{j}^{i}=0$; (2) $t_{4}^{1}=t_{4}^{2}=t_{4}^{3}=1$, all other $t_{j}^{i}=0$; (3) $t_{2}^{1}=t_{2}^{2}=t_{3}^{3}=1$, all other $t_{j}^{1}=0$; (4) $t_{2}^{1}=t_{2}^{2}=t_{4}^{3}=1$, all other $t_{j}^{1}=0$; (5) $t_{2}^{1}=t_{2}^{2}=t_{7}^{3}=1$, all other $t_{j}^{1}=0$. There are 9 other Nash equilibria similar to those described in (3), (4), and (5) above where two fund-raisers put all their weight on a shared tie and the third fund-raiser is left to put all his weight on a donor shared with no other fund-raisers. There are also several mixed Nash. For instance there is a mixed Nash where $t_{2}^{1}=t_{2}^{2}=t_{7}^{3}=1$ each with probability $1 / 2$ and $t_{3}^{1}=t_{6}^{2}=t_{5}^{3}=1$ each with probability $1 / 2$ and all other $t_{j}^{1}=0$. There are also a number of mixed Nash similar to the following one where $t_{2}^{1}=t_{2}^{2}=1$ and fund-raiser 3 plays $t_{3}^{3}=1, t_{4}^{3}=1, t_{7}^{3}=1$ all with positive probability. Note that pure Nash (2) above where all fund-raisers solicit donor 4 generates the highest payoff for the fund-raisers. However, at all of the other Nash equilibria, donor 4 is either unsolicited or solicited by only one fund-raiser.

As the above example shows the number of Nash equilibria can be quite large for the case where $f^{\prime \prime}>0$. Next, we try to refine the number of Nash equilibria using stochastic stability.

Dynamics. Let time be discrete and represented as $\{0,1$, $2, \ldots, \tau, \ldots\}$. Let $t(\tau-1)$ be a vector representing the time $t(\tau-1) \equiv\left\{t^{1}(\tau-1), t^{2}(\tau-1), \ldots, t^{m}(\tau-1)\right\}$ the fund-raisers spend soliciting donations in period $(\tau-1)$. At each period $\tau$, one fund-raiser $i$ is chosen at random to update his strategy, $t^{i}$. Fund-raiser $i$ will choose a myopic best response to $t^{-i}(\tau-1)$. After this choice is made, there is a small probability $1>\varepsilon>0$ that another strategy is chosen instead. Thus, with probability $\varepsilon$ there is a mistake and the strategy $t^{i}(\tau)$ is chosen at random with each possible $t^{i}$ receiving positive probability.

Stochastic Stability. This process determines a finite state, irreducible, aperiodic Markov chain and has a unique invariant probability distribution $\mu^{\varepsilon}$ over strategy configurations. A strategy $t$ is stochastically stable if it is in the support of $\mu=$ $\lim _{\varepsilon \rightarrow 0} \mu^{\varepsilon}$. (See Freidlin and Wentzell [28] or Young [29] for further discussion of stochastic stability.)

Let $g^{1}$ represent a network such that there is exactly one donor, say donor 1, that all fund-raisers are tied to; all other donors have strictly less than $m$ ties.

Proposition 13. Assume $f^{\prime}>0$ and $f^{\prime \prime}>0$. At the unique stochastically stable equilibrium of the average donation sharing game with any $g^{1}, t_{1}^{i}=1$ for all $i \in M, m \geq 2$.

Proof. First we show that setting $t_{1}^{i}=1$ for all $i \in M$ is a Nash equilibrium. Given all $k \neq i, k \in M$ set $t_{1}^{k}=1$, we show that $i$ 's best response is to set $t_{1}^{i}=1$. Assume to the contrary that $t_{1}^{i}=a$ such that $0 \leq a<1$ and that $t_{j}^{i}=1-a$ for some $j \in N$. Then $\pi^{i}=f(1-a)+(a /(n-1+a)) f(n-1+a)$. Since $f^{\prime}>0$ and $f^{\prime \prime}>0, f(1-a)+(a /(n-1+a)) f(n-1+a)<(1 / n) f(n)$, which is $i$ 's payoff if $t_{1}^{i}=1$. Similarly, for any other $t^{i} \neq(1,0, \ldots, 0)$, $i$ s payoff will be smaller than $(1 / n) f(n)$. Thus, $i$ sets $t_{1}^{i}=1$ and our proposed strategy is a Nash equilibrium. (Note that at all Nash equilibrium each fund-raiser $i$ sets $t_{j}^{i}=1$ for some $j \epsilon$ $N$ since i's payoff, $(t /(t+a)) f(t+a)$, from soliciting a donor who others are soliciting with total time $a \geq 0$, is increasing in both $t$ and $a$; thus $i$ would like to spend all his time soliciting the donor with the largest such $a$.)

Let $t^{*}$ represent the equilibrium where $t_{1}^{i}=1$ for all $i \in M$. If $t^{*}$ is the unique Nash equilibrium of the game, then it is trivially stochastically stable. Next, we assume that there is at least one other Nash equilibrium say $\widetilde{t}=\left(\widetilde{t}^{1}, \widetilde{t}^{2}, \ldots, \widetilde{t}^{m}\right)$. Let $m \geq 3$, we will consider the case of $m=2$ below. To leave state $t^{*}$ and move to state $\widetilde{t}$ takes at least $\lceil\mathrm{m} / 2\rceil$ trembles 
(where $\lceil a\rceil, a \in \mathbb{R}$, represents the integer $z \in \mathbb{Z}$ closest to $a$ such that $z \geq a$ ). To see this note that if $\lceil m / 2-1\rceil$ trembles occur, then the largest payoff a trembling agent could have is if all trembling fund-raisers solicit the same new donor resulting in a payoff for each trembling agent of $(1 /\lceil m / 2-1\rceil) f(\lceil m / 2-1\rceil)$; this is because $(1 / t) f(t)$ is strictly increasing in $t$ whenever $f^{\prime}>0$ and $f^{\prime \prime}>0$. If the trembling agent goes back to his $t^{*}$ strategy his payoff would be $(1 /(m+1-\lceil m / 2-1\rceil)) f(m+1-\lceil m / 2-1\rceil)$ which is larger than $(1 /\lceil m / 2-1\rceil) f(\lceil m / 2-1\rceil)$. Thus, $\lceil m / 2-1\rceil$ trembles are not enough to leave state $t^{*}$.

However, to go from state $\tilde{t}$ to state $t^{*}$ takes at most $\lceil m / 2-1\rceil$ trembles for $m \geq 3$. To see this notice that at the $\tilde{t}$ equilibrium not all fund-raisers are soliciting the same donor, since in $g^{1}$ there is only one donor who is linked to all fund-raisers and this donor is solicited by all fund-raisers at the $t^{*}$ equilibrium. Thus, at the $\tilde{t}$ equilibrium, there exists a donor, say 2 , such that the number of fund-raisers soliciting 2 is less than or equal to $m / 2$. First, assume that the number of fund-raisers soliciting 2 is less than $m / 2$. Let $\lceil m / 2-1\rceil$ fund-raisers not soliciting 2 tremble to the $t^{*}$ equilibrium. Then any fund-raiser soliciting 2 has incentive to move to the $t^{*}$ equilibrium as his payoff will increase from at most $(1 /\lceil m / 2-1\rceil) f(\lceil m / 2-1\rceil)$ to $(1 /(\lceil m / 2-1\rceil+1)) f(\lceil m / 2-1\rceil+$ $1)$. Similarly, all remaining fund-raisers will move to the $t^{*}$ equilibrium. Second, let the number of fund-raisers soliciting 2 equal $m / 2$. Again let $\lceil m / 2-1\rceil$ other fund-raisers tremble to the $t^{*}$ equilibrium. Next, the remaining fund-raiser who is also not soliciting donor 2 will move to the $t^{*}$ equilibrium as his payoff will increase from $f(1)$ to $(1 /(\lceil m / 2-1\rceil+$ 1)) $f(\lceil m / 2-1\rceil+1)$. Similarly, all remaining fund-raisers will move to $t^{*}$. Thus, $\lceil\mathrm{m} / 2-1\rceil$ trembles are enough to move from state $\widetilde{t}$ to state $t^{*}$.

Lastly, consider the case where $m=2$ and where an alternative Nash, $\tilde{t}$, exists. To move from $t^{*}$ to $\tilde{t}$ takes two trembles, since if either fund-raiser is soliciting donor 1 , then the other fund-raiser has incentive to also solicit donor 1 . However, to leave $\tilde{t}$ and move to $t^{*}$ takes just one tremble. Here if one fund-raiser trembles to his $t^{*}$ strategy, then the other fund-raiser will also switch to solicit donor 1. By Young [30] only states with the minimum resistance are stochastically stable; so $t^{*}$ is stochastically stable while $\tilde{t}$ is not.

Notice here that the unique stochastically stable state coincides with the efficient Nash equilibrium, since all players are better off soliciting the same donor when the donation function is increasing and convex.

Remark 14. If the network has multiple donors each of whom are linked to all fund-raisers, then the above proof can be modified to show that there will be multiple stochastically stable states. At each stochastically stable state, each fundraiser spends all his time soliciting the same donor.

\section{Conclusion}

We showed that donation requests are influenced by the fund-raiser donor network and in particular by whether or not a fund-raiser shares a donor tie with other fundraisers. For instance, in an incomplete network with extreme donor fatigue fund-raisers spend more time soliciting donors shared with other fund-raisers as compared with un-shared donor ties. If donors experience instead mild donor fatigue, then fund-raisers prefer to solicit donors un-shared with other fund-raisers. Additionally, we examined the case of no donor fatigue and showed that multiple equilibria may exist; stochastic stability was used to refine the number of equilibria.

A policy implication for fund-raisers is that fund-raisers should examine the fund-raiser donor network and the level of donor fatigue and use this information when deciding how much time to spend soliciting particular donors. Fundraisers can learn the fund-raiser donor network by joining pools in which many fund-raisers share information about donors; we know such pools are quite prevalent from the popular press, see Kadet [31]. Additionally, if a fund-raiser is spending a lot of time with a donor in order to secure a large donation, then the fund-raiser will probably learn from the donor whether or not he is also being solicited by others. Fund-raisers can learn the level of donor fatigue by observing a donor's donation history; since donor fatigue occurs when an increase in solicitation efforts results in a smaller marginal donation, the level of donor fatigue could be learned by analyzing past and present donor databases. If a fund-raiser learns that donor fatigue is mild, then he may be better off not joining pools where he must share information about his donors with other fund-raisers, while if donor fatigue is severe, then joining such pools would be beneficial.

If a fund-raiser learns of a set of donors who are solicited by only a few or no other fund-raisers and if donor fatigue is mild, then the fund-raiser may want to focus his efforts on this set of donors. If a fund-raiser learns of a set of donors who are solicited by numerous other fund-raisers and if donor fatigue is severe, then the fund-raiser may actually want to spend time soliciting these donors as although doing so may not increase these donors' total donations to all fundraisers much it may instead allow this fund-raiser to "steal" donations that would otherwise go to someone else.

The model may be extended in several ways. For instance, we could allow heterogeneous donors to exist on the same network where some donors are more willing to donate money than others. It would be interesting to see how the placement of such a donor onto the network would influence donation requests. As the current model is already quite complicated, solving this issue is beyond the scope of the current paper and is left for future research.

Additionally, we have assumed for simplicity that the network is exogenous; however, it would be interesting to allow the network to be endogenous. For instance, perhaps every period fund-raisers could learn of new donors and have a chance to add these new links as well as a chance to sever existing links. Here, if donor fatigue is mild, then fund-raisers may prefer to sever links shared with others and attempt to find new unlinked donors to link to by purchasing donor lists or through mail out campaigns or by sponsoring fundraising events where existing donors are encouraged to bring their friends. If donor fatigue is extreme, then fund-raisers 
may want to buy or share information about potential donors and add ties to donors who are already linked to other fundraisers.

\section{Acknowledgments}

The author thanks Chi-ang Lin, Maria Arbatskaya, Philip Grossman, Laura Kalambokidis, and David Yi for valuable comments and criticisms.

\section{References}

[1] J. Andreoni, "Charitable giving," in The New Palgrave Dictionary of Economics, S. Durlauf and L. Blume, Eds., Palgrave Macmillan, 2nd edition, 2008.

[2] M. Hall, C. W. Barr, M. Easwaramoorthy, S. W. Sokolowski, and L. M. Salamon, The Canadian Nonprofit and Volunteer Sector in Comparative Perspective, Imagine Canada, Toronto, Canada, 2005.

[3] B. K. Yörük, "How responsive are charitable donors to requests to give?" Journal of Public Economics, vol. 93, no. 9-10, pp. 11111117, 2009.

[4] B. K. Yörük, "How responsive are charitable donors to requests to give?" Working Paper Version, Boston College, 2007.

[5] J. Andreoni, "Philanthropy," in Handbook of Giving, Reciprocity and Altruism, S. C. Kolm and J. Mercier Ythier, Eds., pp. 12011269, North Holland, Amsterdam, The Netherlands, 2006.

[6] J. Andreoni and A. A. Payne, "Do government grants to private charities crowd out giving or fund-raising?" American Economic Review, vol. 93, no. 3, pp. 792-812, 2003.

[7] B. Keegan, Fundraising for Non-Profits: How to Build a Community Partnership, Harper Collins, New York, NY, USA, 1994.

[8] S. Dellavigna, J. A. List, and U. Malmendier, "Testing for altruism and social pressure in charitable giving," The Quarterly Journal of Economics, vol. 127, no. 1, pp. 1-56, 2012.

[9] M. Mungan and B. K. Yörük, "Fundraising and optimal policy rules," Mimeo, University at Albany, SUNY, 2009.

[10] L. M. Marx and S. A. Matthews, "Dynamic voluntary contribution to a public project," Review of Economic Studies, vol. 67, no. 2, pp. 327-358, 2000.

[11] M. Bagnoli and B. L. Lipman, "Provision of public goods: fully implementing the core through private contributions," Review of Economic Studies, vol. 56, no. 4, pp. 583-601, 1989.

[12] J. Meer and H. S. Rosen, "The ABCs of charitable solicitation," Journal of Public Economics, vol. 95, no. 5-6, pp. 363-371, 2011.

[13] M. van Diepen, B. Donkers, and P. H. Franses, "Dynamic and competitive effects of direct mailings: a charitable giving application," Journal of Marketing Research, vol. 46, no. 1, pp. 120-133, 2009.

[14] J. Andreoni and J. M. Rao, "The power of asking: how communication affects selfishness, empathy, and altruism," Journal of Public Economics, vol. 95, no. 7-8, pp. 513-520, 2011.

[15] M. O. Jackson, "An overview of social networks and economic applications," in Forthcoming in the Handbook of Social Economics, J. Benhabib, A. Bisin, and M. O. Jackson, Eds., Elsevier, 2009.

[16] M. O. Jackson and A. Wolinsky, "A strategic model of social and economic networks," Journal of Economic Theory, vol. 71, no. 1, pp. 44-74, 1996.
[17] A. Calvó-Armengol and M. O. Jackson, "The effects of social networks on employment and inequality," American Economic Review, vol. 94, no. 3, pp. 426-454, 2004.

[18] Y. Bramoullé and R. Kranton, "Risk-sharing networks," Journal of Economic Behavior and Organization, vol. 64, no. 3-4, pp. 275-294, 2007.

[19] M. Fafchamps and S. Lund, "Risk-sharing networks in rural Philippines," Journal of Development Economics, vol. 71, no. 2, pp. 261-287, 2003.

[20] R. E. Kranton and D. F. Minehart, "Competition for goods in buyer-seller networks," Review of Economic Design, vol. 5, no. 3, pp. 301-331, 2000.

[21] R. E. Kranton and D. F. Minehart, "A theory of buyer-seller networks," American Economic Review, vol. 91, no. 3, pp. 485$508,2001$.

[22] M. O. Jackson and A. Watts, "The evolution of social and economic networks," Journal of Economic Theory, vol. 106, no. 2, pp. 265-295, 2002.

[23] M. O. Jackson and A. Watts, "On the formation of interaction networks in social coordination games," Games and Economic Behavior, vol. 41, no. 2, pp. 265-291, 2002.

[24] S. Skaperdas, "Contest success functions," Economic Theory, vol. 7, no. 2, pp. 283-290, 1996.

[25] H. Moulin, "The price of anarchy of serial, average and incremental cost sharing," Economic Theory, vol. 36, no. 3, pp. 379405, 2008.

[26] H. Moulin and A. Watts, "Two versions of the tragedy of the commons," Review of Economic Design, vol. 2, no. 1, pp. 399421, 1997.

[27] A. Watts, "Uniqueness of equilibrium in cost sharing games," Journal of Mathematical Economics, vol. 37, no. 1, pp. 47-70, 2002.

[28] M. I. Freidlin and A. D. Wentzell, Random Perturbations of Dynamical Systems, Springer, New York, NY, USA, 1984.

[29] H. P. Young, Individual Strategy and Social Structure, Princeton University Press, Princeton, NJ, USA, 1998.

[30] H. P. Young, "The evolution of conventions," Econometrica, vol. 61, no. 1, pp. 57-84, 1993.

[31] A. Kadet, "Smart money: is your favorite charity spying on you?" The Wall Street Journal, vol. 16, 2010. 


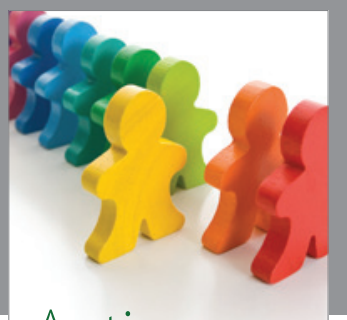

Autism

Research and Treatment
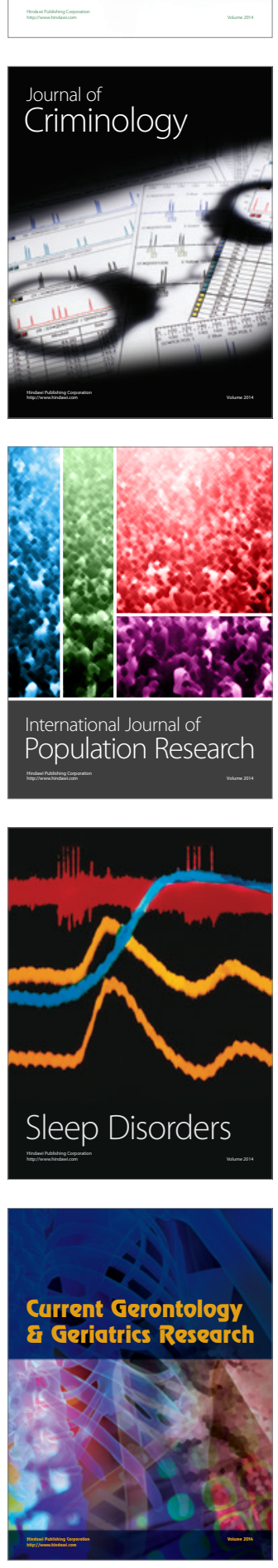
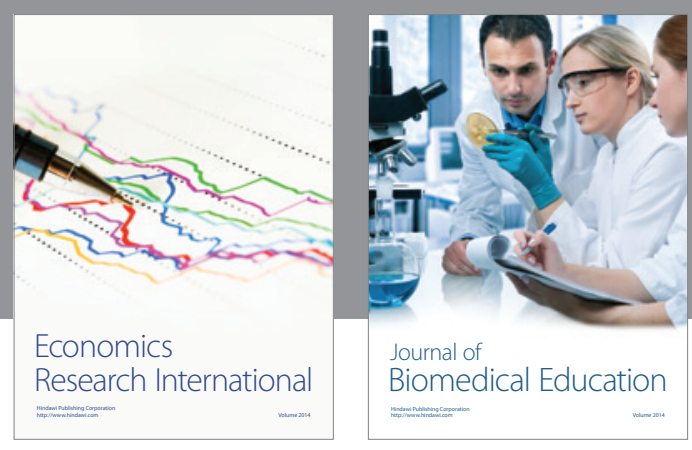

Journal of

Biomedical Education

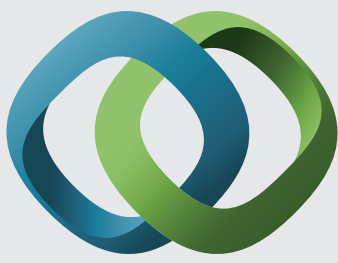

\section{Hindawi}

Submit your manuscripts at

http://www.hindawi.com
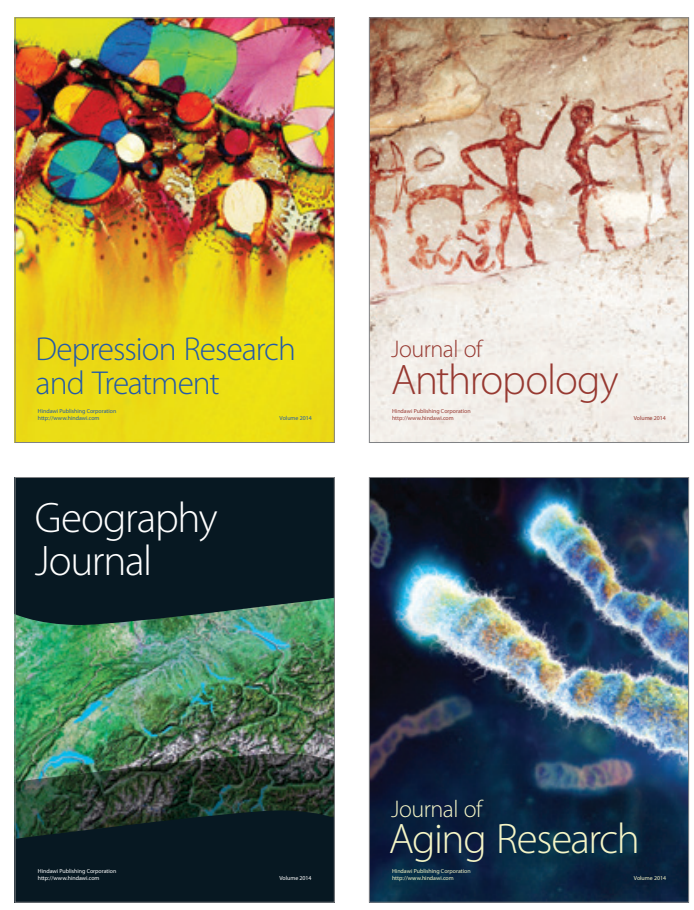

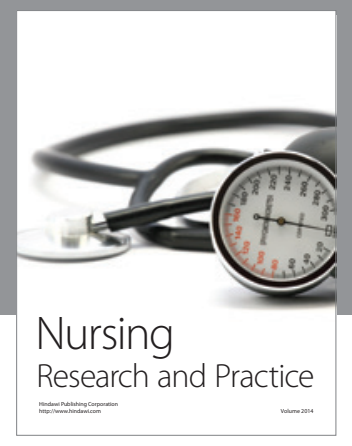

Nursing

Research and Practice

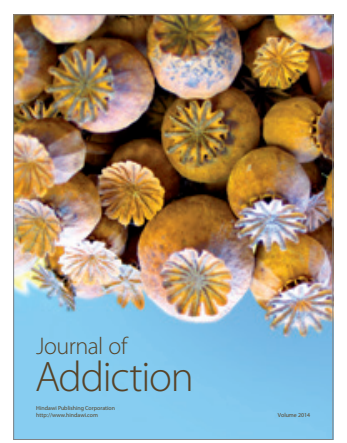

Child Development

Research

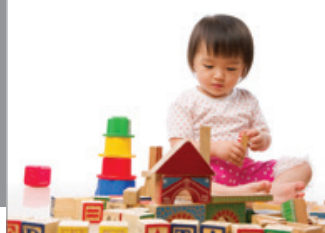

迥
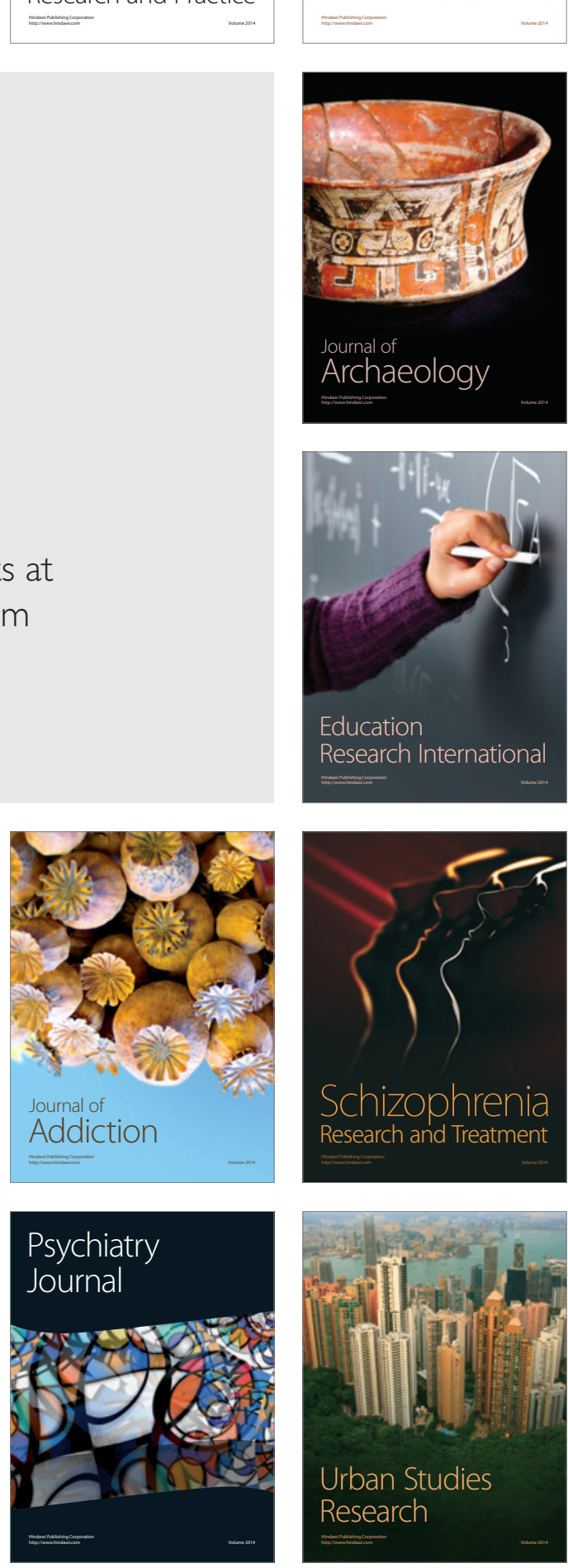